\title{
Inovação em Saúde Mental: subsidios à construção de práticas inovadoras e modelos avaliativos multidimensionais
}

I ${ }^{1}$ Maria Lucia Magalhães Bosi, ${ }^{2}$ Liliane Brandão Carvalho,

${ }^{3}$ Maria Aparecida Alves Sobreira, ${ }^{4}$ Verônica Morais Ximenes,

${ }^{5}$ Mariana Tavares Cavalcanti Liberato, ${ }^{6}$ Maria Gabriela Curubeto Godoy I

Resumo: Este estudo tem como objetivo problematizar e demarcar conceitualmente a categoria inovação, com vistas a subsidiar a construção de práticas inovadoras e modelos avaliativos multidimensionais em saúde mental. Inovação, termo bastante presente em âmbitos como administração, tecnologia e, grosso modo, nas ciências duras, é aqui reconfigurando como processo, apontando para movimentos de mudança potencializadores do surgimento de novos modos de interação, saberes e práticas, cujo caráter é de superação da lógica anterior, considerada então tradicional. Com base em revisão e posterior diálogo com a literatura concernente à saúde mental e ao conceito de inovação nesse âmbito, propõese a incorporação das dimensões epistêmica, ético-política e ecológica como elementos essenciais à construção de práticas e modelos de cuidado em saúde mental, bem como propostas voltadas a avaliar inovações. Na dimensão epistêmica, incluise o necessário reconhecimento do adoecimento em sua dimensão existencial de sofrimento, superando taxonomias e nomenclaturas nas quais ainda predomina o rótulo da loucura, que pouco ou nada nos diz sobre o homem, sua existência e os condicionantes sócio-históricos de seu sofrimento.

A dimensão ético-política compreende a necessidade de delimitar concepções de saúde mental que englobem práticas transformadoras da realidade social, incorporando uma grupalidade pautada na circularidade do cuidado, criatividade e consciência social. Por fim, a dimensão ecológica designa conectividade na acepção de uma reconexão com suas raízes sociais e históricas e com o sagrado, favorecendo processos que superem a alienação e facilitem o desenvolvimento do fortalecimento pessoal e coletivo.

> Palavras-chave: inovação, saúde mental, cuidado em saúde; saúde coletiva; saúde pública.

\author{
1 Coordenadora do Laboratório \\ de Avaliação e Pesquisa \\ Qualitativa em Saúde. \\ Faculdade de Medicina, \\ Departamento de Saúde \\ Comunitária, Universidade \\ Federal do Ceará. Endereço \\ eletrônico: LAPQS@ \\ yahoogrupos.com.br \\ 2 Pesquisadora LAPQS; \\ doutoranda em Saúde \\ Coletiva (UFC/UECE/UNIFOR); \\ professora do curso de \\ Psicologia da Universidade de \\ Fortaleza. \\ ${ }^{3}$ Pesquisadora LAPQS; mestre \\ em psicologia; professora \\ assistente do Instituto Federal \\ de Educação, Ciência e \\ Tecnologia - Campos Sousa/PB. \\ ${ }^{4}$ Pesquisadora LAPQS; \\ professora da Pós-graduação \\ em Psicologia, Departamento \\ de Psicologia, Universidade \\ Federal do Ceará. \\ ${ }^{5}$ Pesquisadora LAPQS; \\ doutoranda em Psicologia \\ (UFRN); professora substituta \\ FAFIDAM/UECE. \\ ${ }^{6}$ Pesquisadora LAPQS; medica \\ psiquiatra; doutora em Saúde \\ Coletiva (UFC/UECE/UNIFOR).
}

Recebido em: 20/09/2011. Aprovado em: 29/12/2011. 
Este artigo toma como objeto a problematização e a demarcação conceitual da categoria inovação, de maneira a subsidiar a construção de práticas inovadoras e, por extensão, modelos avaliativos multidimensionais em saúde mental. Para tanto, impôs-se uma aproximação ao ideário da Reforma Psiquiátrica brasileira e outros campos discursivos, nos quais o referido conceito circula, que permitisse ir além dos enunciados do que se considera inovação nesse âmbito, evidenciando interfaces e possíveis subsídios a práticas inovadoras voltadas à desinstitucionalização e à inclusão social em saúde mental.

O interesse por esse tema se impôs no curso de uma investigação ${ }^{1}$ voltada à avaliação de um movimento comunitário em saúde mental, cujo histórico já alcança 15 anos. Mesmo não institucionalizado enquanto política pública, o referido movimento iniciou práticas de cuidado dirigidas à população pobre destituída desses serviços no seu entorno e submetida a condiçōes de vida extremamente precárias em um município do Nordeste do Brasil. Essa inciativa vem sendo considerada inovadora em vários espaços, ainda que não submetida a avaliações e sem estudos sobre a mesma na literatura cientifica.

Dado nosso interesse em estudá-lo enquanto inovação, ao nos aproximarmos da literatura concernente a essa desafiadora categoria analítica, observamos ser tradicionalmente empregada no campo das chamadas hard sciences, em especial em estudos sobre tecnologias, figurando também no âmbito da administração. Nesses domínios, recebe significados restritos e bastante específicos, distantes do campo da saúde (mental).

Contudo, autores como Barros et al. (2007) apontam outras vertentes mais próximas às intencionadas nesta discussão, concebendo inovação na interface do cuidado em saúde. Nessa perspectiva, seus contornos se alinham a concepções embasadas no campo da reabilitação psicossocial, favorecendo a autonomia, o poder contratual, a desconstrução de práticas fundamentadas na objetividade da doença mental e a (re)construção de outras direcionadas às necessidades dos usuários dos sistemas de saúde. Assim, vamos ao encontro dos que postulam que o processo de desinstitucionalização da loucura não se consolidará apenas criando fronteiras mais alargadas, mediante mecanismos menos excludentes e mais permeáveis. Há que se diluir tais fronteiras, permitindo novos atravessamentos, deslocando territórios - concretos e subjetivos - no sentido de delinear alternativas 
de acolhimento dos diferentes tipos de sofrimento engendrados em uma sociedade marcada por várias formas de exclusão (INOJOSA, 2002).

Diante do exposto, intencionamos nesta exposição demarcar o conceito de inovação e, com base nessa delimitação, desdobrá-lo em alguns elementos que subsidiem práticas inovadoras no campo da saúde mental, bem como, por extensão, modelos voltados à sua avaliação, a partir da interlocução teórica com autores como Amarante (1992, 1994, 2003), Dimenstein (2004), Freire (1979, 1983), Marinotti (2002), Martín-Baró (1985, 1998), Rossi (2005), Sawaia (1996) e Santos (2010).

Entendemos que tal construção se mostra oportuna, tanto para o campo discursivo da Reforma Psiquiátrica, como, sobretudo, para examinarmos outras perspectivas de práticas de cuidado em saúde mental, enquanto inovação no campo da Saúde Coletiva, algumas delas ainda não institucionalizadas ou pouco conhecidas.

\section{Inovação em saúde (mental): o que isso significa?}

Segundo o dicionário Aurélio (FERREIRA, 1999), o termo inovação origina-se do latim innovatione e se define pelo ato ou efeito de inovar, significando por extensão novidade, e trazendo em seu bojo o caráter da emergência do novo e da mudança. Conforme já aludido, esse termo circula com mais frequência nas áreas administrativas e organizacionais, nas quais é tomado como elemento crucial ao desenvolvimento econômico e social de um país (CONDE; ARAÚJO-JORGE, 2003). Em termos institucionais, possibilita ampliar a capacidade de absorção e utilização de novos conhecimentos, tornando as organizaçoos mais produtivas e, assim, mais competitivas - lócus central da inovação - do que as que não investem na geração de inovações.

Tal posição é corroborada por Barbieri et al. (2010), que relacionam inovação com desenvolvimento sustentável de um negócio, incluindo o aspecto econômico, o respeito ao meio ambiente e a promoção da justiça e inclusão social. Assim, não basta inovar a qualquer custo, mas antes, considerando as três dimensões próprias da sustentabilidade: social - impacto da inovação no ambiente interno e no entorno da organização; ambiental - preocupação com os impactos ambientais; e econômica - obtenção de lucro e vantagens competitivas que propiciem sobreviver no mercado. 
Entender inovação na contemporaneidade, no campo específico das ciências tecnológicas, ressaltam ainda Conde e Araujo-Jorge (2003), é enfatizar as noções de interatividade, de inclusão de novos atores e do conceito de rede - reflexo das dinâmicas interativas que envolvem as contínuas e múltiplas conexões entre os diversos atores ou esferas. Nessa vertente, é significativa a identificação com inovação tecnológica, ou seja, com geração de novos produtos e processos no âmbito do setor produtivo.

Não é nosso intuito recensear os elementos que circulam no debate dessas esferas externas ao campo da saúde, cujo teor os parágrafos anteriores servem como ilustração. Para os propósitos da presente discussão, importa-nos mencionar que o contato com essa literatura nos levou a interrogar se e como tais perspectivas deveriam ser consideradas no campo das relações, saberes e práticas vivenciadas no cotidiano da saúde mental, ao examiná-las no sentido de reconhecê-las como inovação. Seria possível considerar as mesmas dimensões em um âmbito voltado ao cuidado e ao sofrimento humanos?

Para tanto, como primeiro exercício, pareceu-nos útil aprofundar a análise do termo inovação, aproximando-o à discussão sobre tecnologia social definida como: "Conjunto de técnicas, metodologias transformadoras, desenvolvidas e/ou aplicadas na interação com a população e apropriadas por ela, que representam soluções para inclusão social e melhorias das condições de vida” (ITS, 2004, p. 130). A participação e a aprendizagem seriam, portanto, elementos essenciais no escopo das tecnologias sociais, exigindo dialogicidade.

Quanto à saúde mental, sabemos, cada vez mais, haver demanda por relações pautadas pelo respeito e pelo acolhimento e menos pela anulação da diferença e mera aplicação de técnicas (CARVALHO; BOSI; FREIRE, 2008). A efetivação desse modo de estar diante do outro dar-se-á pela "produção de políticas públicas locais e intersetoriais e de redes e serviços substitutivos e territoriais que visem à superação do modelo asilar, à produção de direitos e à invenção de um novo lugar social para a experiência da loucura."(NICÁCIO; CAMPOS, 2004, p. 72). Desse modo, é necessário reconfigurar tanto o objeto de intervenção - não mais a doença e sim o sujeito social doente - quanto à sua finalidade: não mais a remissão dos sintomas e sim as necessidades de saúde propriamente humanas (BARROS et al., 2007). 
Inovação revela-se assim como um dos desafios decisivos para a transformação do saber e do fazer dos profissionais no cotidiano do cuidado em saúde mental visando a organizar novas bases teóricas e pr áticas de condução dos projetos assistenciais e, consequentemente, a invenção de novos modos de produzir saúde. Saúde aqui considerada coprodução (MARINOTTI, 2002), em que homem e mundo se atualizam mutuamente, construindo e atribuindo significados.

Retomando como ilustração a emergência do primeiro serviço substitutivo ao modelo asilar no Brasil, pautado no território e na promoção do cuidado integral à demanda dos considerados usuários graves, a ênfase foi transformar o modo de responder ao apelo desse usuário:

O que é fundamental enfatizar é que a aproximação, a presença e a disponibilidade da equipe para entrar em relação, reconhecendo necessidades, mediando relações, lidando com os conflitos, potencializando saberes, transformando e diversificando as respostas, geravam um novo contexto de relações e de possibilidades [...] [marcada pelo] aprender a lidar e produzir diálogos com múltiplos atores: os usuários, as pessoas de sua rede relacional, os familiares, os vizinhos, as pessoas do território. (NICÁCIO; CAMPOS, 2004, p. 75)

Tal posicionamento implica responsabilidade cuja efetivação se dá na produção de um novo modo de cuidado no campo da saúde mental. Novo modo constituído pelo estar-com (NICÁCIO; CAMPOS, 2004), pelo diálogo e acolhimento à pessoa em experiência de adoecimento; bem como pela escuta interessada e possibilidade de encontros. A urgência é por um novo ethos, uma nova atitude para com esse usuário, favorecendo a emergência de um novo sujeito.

Abordar inovação em saúde mental significa, portanto, reiterar a necessidade de cuidado como uma atitude ética pautada no conceito de reabilitação psicossocial, cuja implicação maior é a desconstrução de práticas fundadas na objetivação da doença mental e na (re) construção de práticas que considerem as alteridades.

Em Lévinas (1982), o outro ocupa lugar essencial, não passível de tematização ou cristalização que anulem a diferença. Em suas reflexões, o filósofo nos remete a uma escuta ética, na qual o outro não pode ser objeto nem meio, qualquer que seja o fim, exigindo-nos uma nova via: a dos sentidos, dos afetos e da afetação pela alteridade. Essa dimensão ética impóe responsabilidade radical pelo outro de modo desinteressado, em termos levinasianos, implicando, sobretudo, um 
primeiro gesto ético: "A deposição da soberania pelo 'eu' é a relação social com outrem, a relação des-inter-essada. Escrevo-a em três palavras para realçar a saída do ser que ela significa." (LEVINAS, 1982, p. 43).

Reabilitar é direcionar a atenção a partir da tomada de responsabilidade e do estabelecimento de relações que favoreçam maior cidadania, autonomia capacidade de gerar outras normatividades para a própria vida-e poder contratual, no qual o profissional da saúde faz uso de seu poder na relação para aumentar o poder do usuário. Fatos que levam Nicácio e Campos (2004) a afirmarem ser fundamental, na produção de práticas inovadoras, a problematização do mandato social e do papel dos técnicos e profissionais na rede substitutiva e territorial.

Quanto a isso, cabe resgatar o trabalho da psiquiatra Nise da Silveira, pioneira na crítica ao modelo asilar no país. Com uma trajetória de vanguarda, cujas ações ocorreram aproximadamente quarenta anos antes da Reforma Psiquiátrica brasileira, propôs-se a deslocar a ênfase do asilo e do diagnóstico para a questão terapêutica. A inovação clínica em sua prática deu-se pela experimentação, invenção, criatividade; bem como pelo afeto, cuidado e construção de passagens para a autonomia (CASTRO; LIMA, 2007).

No entanto, muitas décadas depois, ainda persistem práticas assistenciais estruturadas em relações hierárquicas, de pouca interação com o saber-fazer, o que leva Franco (2007) a apontar outro aspecto importante para experiências inovadoras de produção de cuidado: a reorganização do processo de trabalho centrada nas necessidades dos usuários.

Em discussão voltada ao significado de inovação no campo da saúde pública, as pesquisadoras Fung, Simpson e Packer (2010) elencam algumas características desse tipo de intervenção que confluem ao que aqui postulamos: uma ação nova e diferente para modelos já estabelecidos; algo aplicável em toda a população, não apenas em grupos específicos; e uma intervenção já existente, utilizada, porém, de forma diferente.

Sabendo que pensar saúde não é prerrogativa apenas dos serviços vinculados ao setor, concordamos com a compreensão de Serapioni (2005) quanto ao cuidado familiar constituir o fundamento do cuidado comunitário, valorizando o contexto social da vida doméstica na promoção da saúde. Torna-se necessário à equipe profissional pautar sua atuação por uma capacidade inventiva, interagindo e dialogando com os saberes dos cuidadores ou da própria família, deixando-se 
também afetar. O domicílio se configura como genuinamente lugar de encontro, onde são produzidos "afetamentos" (FRANCO; MERHY, 2008).

Entender o domicílio como lócus de encontro entre o saber técnico-cientifico da equipe e o saber-cuidador dos familiares escapa à racionalidade institucional predominante nos serviços de saúde, orientados pelo modelo tradicional de assistência à saúde. Trata-se de produzir encontros que agucem a capacidade de pactuação - entendida como dimensão de inovação por Franco e Merhy (2008) - potencializadora do caráter de "substitutividade" das tecnologias de cuidado e das praticas profissionais. Assim, inovação pode ser concebida como uma ação participativa, de responsabilidade de diversos atores, não apenas dos profissionais, capaz de romper com os efeitos centralizadores de poder vinculado ao ideário da Reforma Psiquiátrica, complementam Pinheiro e Guizardi (2005). Enquanto ação transformadora, Godoy e Bosi (2007) ressaltam que experiências inovadoras precisam valorizar as atividades que tecem a vida cotidiana e a atuação no território, fomentando o fortalecimento de redes de apoio.

Em síntese, reorganizar e produzir novos modos de cuidado no cotidiano da saúde mental implica fazer dos dispositivos um espaço de encontros e diálogos genuínos, de acolhimento, de afetação e não anulação da diferença. $\mathrm{O}$ interesse deve ser na responsabilidade - no sentido já exposto - e na potencialização de maior autonomia, no sentido da definição de uma ética não heterônoma (MAFFESOLI, 2001), o que por sua vez propiciará a criação de uma nova forma de cidadania (SANTOS, 2010).

No projeto da modernidade, cuja proposta matriz era o equilíbrio - não alcançado - entre os marcos de regulação e de emancipação, cidadania éconsiderada uma via de direitos e deveres gerais e abstratos que reduzem a individualidade e transformam os sujeitos em unidades iguais ou "[...] receptáculos passivos de estratégias de produção, enquanto força de trabalho, de estratégias de consumo, enquanto consumidores, e de estratégias de dominação, enquanto cidadãos da democracia de massas." (SANTOS, 2010, p. 240). É preciso uma nova cidadania que ocorra no marco emancipatório e não no da regulação, como tem ocorrido; e que seja pautada mais em modos de participação, e menos em direitos e deveres, propiciadores de mais espaço para autonomia, criatividade e reflexividade.

Construir práticas inovadoras de atenção à saúde mental, com base nas necessidades das pessoas com a experiência de adoecimento, na articulação de 
todos os atores envolvidos e na valorização da diversidade dos recursos de cada território, implica, sobretudo, produção de novas respostas às situações de crise que possibilitem a superação da demanda de internação no hospital psiquiátrico e a criação de novas práticas de cuidado para com o outro. Assim, tornar os serviços lócus de práticas inovadoras é um grande desafio, haja vista exigir rupturas profundas com o modelo instituído e arraigado socialmente.

Diante do exposto e consoante um dos objetivos deste artigo, inovação é demarcada como um processo, um movimento de mudança, potencializador do surgimento de novos modos de interação, saberes e práticas, cujo caráter é de superação da lógica anterior, a qual passa a ser considerada tradicional em relação ao que irrompe. Enquanto movimento, sua marca é de experimentação, no sentido de criação, construção de passagens e contínuo desenvolvimento. Assim, inovação é aqui concebida como fluxo, tanto no seu caráter de desconstrução, quanto de produção; e também como capacidade inventiva de desalojamentos, reconfiguraçōes, transformações, gerando necessários tensionamentos, tendo em vista as contradições e distintos interesses em jogo.

\section{Alguns subsídios à construção de práticas inovadoras e modelos avaliativos em saúde mental}

Em consonância com a discussão anterior acerca do delineamento do conceito de inovação e tomando-o agora como referência, sistematizaremos alguns subsídios para construção de práticas inovadoras e, por extensão, modelos avaliativos concernentes a inovações que considerem as múltiplas dimensões inerentes ao cuidado no campo da saúde mental. Para tanto, perpassaremos alguns pressupostos, vislumbrando categorias analíticas norteadoras da construção de propostas consoante a complexidade do objeto saúde mental.

Os elementos, ainda que inter-relacionados, podem ser situados em três dimensões distintas, aqui denominadas Epistêmica, Ético política e Ecológica. A inspiração dessa categorização, a despeito das distinções, procede das formulações de Amarante (1994, 2003), quando se refere a quatro dimensões constituintes da Reforma Psiquiátrica brasileira: teórico-conceitual, técnicoassistencial, jurídico-política e sociocultural. Tal como veremos, a essas dimensões se somam outros elementos localizados no diálogo com a literatura, conformando a proposta aqui apresentada. 
Sabendo que as dimensões não devem ser compreendidas em uma lógica de hierarquização ou grau de importância, o pano de fundo para as formulações acerca de inovações em saúde mental se fundamenta no modelo da complexidade. Visando à superação do modelo clássico que reduz e fragmenta os fenômenos, tal proposta resgata o sentido de complexo como:

aquilo que foi tecido junto; [...] há complexidade quando elementos diferentes são
inseparáveis constitutivos do todo (como o econômico, o político, o sociológico, o
psicológico, o afetivo, o mitológico), e há um tecido interdependente, interativo e
interretroativo entre o objeto do conhecimento e seu contexto, as partes e o todo, as
partes entre sí. Por isso, a complexidade é a união entre a unidade e a multiplicidade.
Daí, ela apresentar-se com os traços inquietantes da confusão, do inextricável, da
desordem, da ambiguidade, da incerteza (MORIN; LE MOIGNE, 2002, p. 38).

Ao buscar elementos inovadores, procuramos, portanto, reconhecer articulações entre diferentes lógicas, assumindo relações paradoxais, conflitos e tensões entre as partes e o todo, o indivíduo e a sociedade - sem sacrifícios de um, em detrimento do outro. O pensamento complexo concebe a emergência das potencialidades criativas sem reduzi-las às partes ou ao todo, mas sim, tomandoas como produções concebidas nas inter-retroações entre elas.

Desta forma, cada elemento que subsidia inovações em saúde mental - e sua avaliação - apresentado neste artigo deve ser compreendido em um processo de retroalimentação e interdependência. Sigamos, pois, com a reflexão acerca dos elementos situados em cada uma das dimensões demarcadas como constitutivas para a construção de práticas inovadoras no campo do cuidado - e da avaliação deste - no âmbito da saúde mental.

\section{Epistêmica}

De modo originário, neste plano se incluem questôes relativas à construção do saber no campo da saúde mental. Para tanto, consideramos uma exigência fundamental para práticas inovadoras a ênfase discursiva em uma perspectiva de desinstitucionalização como desconstrução (AMARANTE 1996, 1998), exigindo, no plano prático-discursivo não apenas um novo lugar para a loucura, mas, sobretudo, uma nova relação com a alteridade. Em Amarante (1994, 2003), a dimensão teórico-conceitual aponta a necessidade de redimensionar o objeto da saúde mental, tendo no conceito de desinstitucionalização o aspecto fundamental que aponta para um processo ético-estético de reconhecimento de novas situações que produzem novos sujeitos. 
Confluindo para essa posição, Rotelli (2001) demarca a desinstitucionalização como um movimento de desconstrução do paradigma psiquiátrico da Modernidade e de crítica à compreensão da loucura sob uma ótica mecânica, racionalista e causal unilinear. A Reforma Psiquiátrica não pode ser compreendida como um mero rearranjo administrativo da rede de assistência, haja vista adotar como base a modificação de seu objeto de intervenção, o doente mental, abstratamente concebido, para um sujeito histórico que sofre de um transtorno mental.

Nesse redimensionamento do conceito de loucura, ainda persistem profundos aprisionamentos quando se alia saúde mental a transtorno mental em uma perspectiva mais nosológica. Bezerra Jr (2007) evidencia a encruzilhada com a qual atualmente se depara o movimento da Reforma Psiquiátrica, devendo esclarecer seu horizonte ético e seu projeto de transformação social e subjetiva, sob o risco de sucumbir à burocracia e à institucionalização conservadora.

$\mathrm{Na}$ mesma direção, Rossi (2005) sinaliza que conceitos de saúde mental baseados em critérios estatísticos ou normativos implicam adaptação a uma sociedade e conformação às suas pautas, não sendo garantia de um ordenamento social que funcione de modo não prejudicial à saúde psíquica dos indivíduos. $\mathrm{O}$ mesmo autor se interroga: a quem interessa esta delimitação estatística que valida uma adaptação-conformismo de uma sociedade dividida em classes diferentes, com interesses distintos, sendo uma delas hegemônica?

Para responder a esta indagação, trazemos à discussão as reflexões de MartinBaró $(1985$, 1998) no campo da psicologia social, as quais desafiam o fazer tradicional no campo da saúde mental. Ao romper com a visão de homem abstrato e com a neutralidade da atuação do psicólogo, conclama à adoção do "realismo crítico", referindo-se a uma postura ao mesmo tempo metodológica, epistemológica e política originada de uma forte crítica ao denominado "idealismo metodológico" (MARTÍN-BARÓ, 1998).

Ao priorizar a teoria em detrimento da materialidade da realidade social, o idealismo metodológico pode incorrer no erro de delimitar o contexto real pelo já conhecido e confundir o presente com o possível. Ideologicamente, parte de uma concepção fatalista e anistórica das atividades humanas e de suas relações e fundamenta como unicamente possível a submissão ao sistema social e político hegemônico, ou seja, ao já instituído, impedindo a reinvenção. 
No campo da saúde mental, esse equívoco se reflete, tal como observamos na visão biomédica, na compreensão dos transtornos mentais enquanto provenientes quase que exclusivamente de variáveis individuais, reduzindo pessoas a meros objetos de estudo e de intervenção, abstraindo-as de seus vínculos históricos e sociais. Desse modo, no plano epistêmico, a teorização desvincula-se das experiências vividas e dos contextos macro e micro aos quais se conectam os serviços de saúde. Muitos desses serviços, conforme já aludido, ainda centralizam sua práxis no entendimento da psiquiatria como (única) detentora do discurso competente "que poderia ser assim resumido: não é qualquer um que pode dizer a qualquer outro qualquer coisa em qualquer lugar e em qualquer circunstância” (CHAUÍ, 2007, p. 19). Nesse discurso, as ideias assumem o estatuto de normatização, em que se anulam as diferenças, sendo o particular universalizado em uma imagem especular dos setores dominantes.

A dimensão epistêmica enquanto lócus de inovação implica, assim, necessárias rupturas com o discurso tradicional da biomedicina, com vistas à (re)construção do conhecimento a partir da imersão na realidade; do lidar com o não-saber que habita a vivência com o novo; e das oportunidades de construir novas relações entre sujeitos, pautadas na desconstrução, na criatividade, na afetação. A exigência é sair do discurso competente do especialista ou do burocrata, estranhar o familiar e avaliar quais conceitos embasam as práticas e vice-versa, examinando conexóes entre as partes que conformam a complexidade que constitui a saúde mental como objeto e campo de saberes e de práxis.

\section{Ético-política}

Nesta dimensão, discutiremos a experimentação e a invenção de práticas de cuidado que envolvam a disponibilidade de afetar e ser afetado, bem como os poderes que operam nos processos de exclusão quando recaímos em práticas, relações e concepções manicomiais. Nesse sentido, reconfiguramos algumas propostas que nos inspiraram nesta construção, subsumindo a dimensão técnicoassistencial nesta categoria, por entendermos que a produção do cuidado (ou assistencial) expressa contornos ético-políticos de um modelo - de cuidado ou avaliação deste - e cuja formatação procede dessa ética.

Consoante Sawaia (1996), o sofrimento ético-político é mutilador da vida e, intersubjetivamente, qualificado no modo de tratar o outro e ser tratado, 
1242 retratando a "vivência cotidiana das questôes sociais dominantes em cada época histórica, especialmente a dor que surge da situação social de ser tratado como inferior, subalterno, sem valor, apêndice inútil da sociedade" (SAWAIA, 1996, p. 105). Essa conceituação parece-nos útil ao campo da saúde mental, marcado pela exclusão e estigma. Tal condição leva a um sentimento de fatalismo cuja superação, consoante Martín-Baró $(1998,2009)$ depende de três tarefas urgentes, as quais ampliamos aqui para o campo da saúde mental: a recuperação da memória histórica; a desideologização do senso comum e da experiência cotidiana; e a potencialização das virtudes populares.

Para realizar a primeira, é necessário encontrar as raízes da própria identidade, vislumbrando o futuro como vir a ser. É na busca de elementos do passado, da história da comunidade que as pessoas podem superar um presente psicológico de uma realidade dada como natural e a-histórica. Estes elementos são úteis como facilitadores de processos de luta e conscientização. Em Freire (1983), a conscientização é um processo em que as pessoas se encontram para desvelar a realidade, assumindo o ato ação-reflexão através de relações dialógicas. Nesse encontro, não se recuperam apenas as próprias identidades, mas o orgulho de pertencimento e valorização das tradições e cultura.

$\mathrm{Na}$ segunda tarefa, segundo Martín-Baró (1998), busca-se desideologizar a experiência cotidiana, contribuindo para resgatar a experiência original dos grupos e das pessoas, permitindo formalizar a experiência de sua própria realidade. Processo realizado mediante a participação no cotidiano da vida dos setores populares.

Entendemos a participação em estreita relação com o sentido de competência pessoal e vontade de atuar no espaço público, sendo fundamental no processo de desenvolvimento da saúde mental. Enquanto favorecedora de relações de cuidado consigo, com o outro e com seu entorno, estimula a autonomia das pessoas e grupos na busca da transformação de si mesmo e da sua realidade. $\mathrm{O}$ ato de participar, tal como aqui concebido, implica, portanto, a transformação na maneira do sujeito refletir sobre a sua realidade, reconhecendo-se capaz de apropriar-se desta e recriá-la (FREIRE, 1979, 1983; GÓIS, 2005; VIEIRA, 2008). A participação pressupõe relação dialógica mediante o respeito à cultura do outro e valorização do conhecimento próprio de cada pessoa. Rossi (2005) enfatiza a grupalidade, indo ao encontro do que aqui concebemos como 
participação, e acrescenta outro elemento: a criatividade. Nesta, há o predomínio

de atividades simbólicas e de interação social, passíveis de superar a relação de alienação, facilitando a realização das próprias potencialidades.

Neste ponto, cabe aludir ao conceito deleuziano de linhas de fuga (DELEUZE, 1998), entendidas como o pensamento que questiona os modelos e se propõe a novos encontros nas relações em que foi produzido (SCHUCH et al., 2003). É uma resistência para além da simples ideia de negar algo, é uma vontade ativa de resistir. Nesta linha de compreensão, retomamos a assertiva de Alverga e Dimenstein (2005, p. 55) sobre a desinstitucionalização como um caminho que "não tem fim, não tem modelo ideal, precisa ser inventado incessantemente". Assim, não intencionamos propor um modelo fechado em si mesmo, mas tão somente sinalizar novas possibilidades para modelos analíticos de práticas inovadoras em saúde mental.

Finalmente, a terceira tarefa sugerida por Martín-Baró $(1998,2009)$ implica potencializar as virtudes populares enquanto espaços em que as relações solidárias se manifestam; bem como a fé na capacidade humana, a luta por melhores condições de existência e as tradições populares e religiosas que apontam para a libertação. É construir uma práxis psicossocial marcada pelo pensar sem submissão e pelo afastamento do que causa medo e tristeza (SAWAIA, 1996).

Desse modo, é necessário adentrar nos territórios concretos e subjetivos, a partir dos quais podem constituir-se novos modos de subjetivação que reconfigurem o con-viver, estabelecendo novas perspectivas éticas e de socialibidade. Avançar nessa direção exige, segundo Rossi (2005), delimitar concepções de saúde mental que englobem práticas transformadoras da realidade social, relacionadas com uma consciência critica da mesma e que incorporem além da grupalidade e criatividade - já expostas - o uso do tempo livre e a consciência social. Aquele inclui tempo de descanso, de diversão e de desenvolvimento pessoal; consciência social possibilita a articulação de respostas crítico-reflexivas individuais, grupais e sociais.

Junta-se aos anteriores, ainda nesta segunda dimensão, outro elemento considerado inovador para subsidiar práticas em saúde mental, o qual incide diretamente no plano técnico assistencial: a circularidade do cuidado (MARINOTTI, 2002). Aqui, o desafio maior é cuidar de si sem deixar de cuidar do outro e do mundo, acolhendo as diferenças constitutivas das pessoas, sem desconsiderar as contradições e conflitos inerentes às relações sociais. 
Uma das características dessa circularidade é a valorização da experiência de ser cuidado para transformar-se em cuidador, processo já presente em diversas culturas nas quais o processo de iniciação enquanto curador é ativado a partir da própria vivência de sofrimento e adoecimento. Em diversas abordagens contemporâneas na medicina, na psiquiatria e nas psicoterapias, vem sendo resgatado o ethos do curador ferido, aquele que passou pela dor e se transformou em cuidador (KIRMAYER, 2003). Resgatar a dimensão do curador ferido no âmbito das práticas de saúde é importante na ativação e facilitação do poder de cura interno de cada pessoa.

Retomamos a referência de Gadamer (2002) a outro modo de cuidado em saúde, que precisa pautar-se pela arte da compreensão e do diálogo constituído pelo saber, o fazer e o ser. Esta prática social teria a afetividade como base do cuidado, utilizando a arte, a religião e a ação política como enfrentamento de estruturas e relações que alimentam a passividade e limitam o conhecimento e a reflexão crítica. E não implicaria, como alerta Dimenstein (2004), uma aceitação incondicional do usuário dos serviços de saúde mental, mas o estabelecimento de atitudes e vínculos solidários não focados na doença, mas, sim, na potência de vida e de transformação de cada um na busca por emancipação - busca esta embasada no compromisso social com as transformações de situações de opressão, favorecendo a cidadania.

\section{Ecológica}

Inspirada no princípio Biocêntrico desenvolvido por Capra (1996), Bohm (1998), Levin (1994), Reeves (1986) e Toro (2001), esta terceira dimensão que propomos - guardando sinergia com as anteriores, mas situada em outro plano toma a vida como centro, reconhecendo o mundo como uma rede de fenômenos fundamentalmente interconectados e interdependentes. Ao nos referimos ao conceito de ecologia, o empregamos em uma acepção que conflui para a ecologia profunda de Arne Naess comentada por Capra (1996), quando a propóe como um novo paradigma para aqui designar as relações recíprocas estabelecidas entre os seres humanos e seu meio social, econômico, cultural, o que inclui o plano transcendente (ou espiritualidade, tomada em sentido amplo) - este último ausente no discurso das reformas no setor. Para Capra (1996), a visão Biocêntrica 
avança com relação às visões teocêntrica (Deus como centro e princípio) e antropocêntrica (ser humano como centro e princípio) e delas se diferencia.

Valorizando a conexão com a vida por meio de um homem relacional, ecológico e cósmico e reconhecendo a espiritualidade (que não se confunde com religiosidade) como uma dimensão do ser humano, denominamos ecológica a terceira categoria constitutiva de práticas inovadoras em saúde mental. Ao enfatizarmos o aspecto espiritual, cabe ressaltar que religião e espiritualidade, embora possuam interfaces e, por vezes, justaposições, são fenômenos distintos. Religião vincula-se à crença no direito à salvação, tradiçôes de fé, aceitação de uma realidade sobrenatural e ensinamentos ou dogmas religiosos e seus rituais. Por seu turno, espiritualidade, tal como aqui entendida, diz respeito a qualidades do espírito humano, resultando em produções subjetivo-afetivas como "amor e compaixão, paciência e tolerância, capacidade de perdoar, contentamento, noção de responsabilidade, noção de harmonia - que trazem felicidade tanto para a própria pessoa quanto para os outros" (BOFF, 2001, p. 21).

Comentamos há pouco um importante elemento sinalizado por Martín-Baró (1998), concernente à existência de leituras fatalistas da realidade, tal como nada há a fazer, desencadeadoras de elementos emocionais de resignação frente ao destino, aceitação do sofrimento e dominação, e não mobilização para a vida. A pessoa reduz seu horizonte ao presente, sem memória do passado ou valorização das lutas empreendidas, tendo dificuldade em planejar o futuro, considerado imutável. Tal postura, tantas vezes constatada em nossos estudos e reportada por muito outros autores na literatura, não pode ser superada apenas com novos discursos e práticas de cuidado - há que penetrar na interioridade das pessoas, como produção subjetiva inovadora.

Assim, a questão da espiritualidade, e também das crenças religiosas, parte importante da nossa cultura, ainda que negligenciada em boa parte das discussões no campo da saúde (coletiva), desempenha papel decisivo ante esse fatalismo. Há que reconhecer seu peso na definição dos princípios e valores norteadores da vida social, definindo julgamentos, processamento de informações (dentre elas concepções de saúde), escolhas e modos de lidar com medos e incertezas do cotidiano. Contudo, durante a maior parte do século XX, e cremos ser ainda válido nos dias atuais, Koenig (2007) relata que o 
campo do cuidado à saúde mental subestimou e frequentemente desqualificou as crenças e práticas religiosas das pessoas.

Considerar a espiritualidade no desenvolvimento das práticas de cuidado em saúde mental, entendendo sua natureza, é um propósito que pode inovar quando voltado ao aperfeiçoamento de ações de integralidade da assistência no campo da saúde mental, haja vista a espiritualidade ser compreendida como instrumento terapêutico e de promoção da saúde (PERES; SIMÃO; NARSELLO, 2007). $\mathrm{Na}$ medida em que lida com dimensóes pouco conscientes - ditas pré-reflexivas - do ser, nas quais se fundam motivações e sentidos humanos relacionados a existência, é via de reconexão com as raízes, com o sagrado, podendo favorecer processos que superem a alienação e desenvolvam fortalecimento.

Para além desse componente, o reconhecimento da importância desta terceira dimensão - ecológica - incorpora o pluralismo médico, os saberes e crenças locais sobre a vida e a morte, bem como os distintos modos de enfrentamento da doença. É o movimento da alteridade dos cuidados que manifesta a emergência e circulação de saberes terapêuticos provindos de um ethos não ocidental e não hegemônico (ANDRADE; COSTA, 2010).

A dimensão ecológica se ligaria então a processos de desenvolvimento pessoal e social, mediados por uma profunda implicação com o outro. Ao excluir práticas individualistas, podendo ligar o transcendente a uma libertação pessoal e social, busca um sentido que conduz à superação de processos de alienação, de desvinculação de sua existência.

Resgatar os vínculos primordiais com a natureza e os seres existentes, segundo o princípio biocêntrico, é um caminho para superar a estrutura desagregadora da cultura, uma oportunidade de reconexão com os instintos, com as forças originárias da vida (CAVALCANTE, 2001). Desse modo, a perspectiva biocêntrica, base desta terceira dimensão, avança ao compreender o homem como uma das possíveis manifestações da vida e reconhecer que a sagrada pulsação da natureza em nós exige um posicionamento ético-político.

Em síntese, a dimensão ecológica, enquanto inovação, se refere à potencialização do cuidado em saúde mental facilitador da reconexão com as raízes (conectividade), com o universo, o sistema familiar, a comunidade e o sagrado inerente a cada um. É a oportunidade de um novo aprendizado existencial; de uma nova perspectiva de subjetividade que supere o individualismo e esteja atenta às necessidades 
sociais; e de construção de uma nova ética com vistas a uma sociedade mais amorosa e justa, na qual cada pessoa, ao comprometer-se com a própria vida, se apropria do seu lugar no mundo. Esse processo de fortalecimento pode gerar intensas mudanças na forma de pensar e sentir o universo, e de entender a pessoa em sua totalidade e responsabilidade no que concerne a tecer as infinitas tramas para seu próprio destino, do qual passa a ser sujeito.

\section{Considerações finais}

Os avanços no campo da saúde mental apontam a exigência de construção de práticas inovadoras voltadas à desinstitucionalização e à inclusão social, pautadas por novos horizontes éticos, materializados em uma rede de saúde mental centrada no território. Rede esta marcada pela defesa de um modo mais humanizado de cuidado, menos excludente, e pelo reconhecimento dos determinantes biopsico-socioculturais do processo de adoecimento, em que a saúde passa a ser considerada um processo em que o sujeito se atualiza com o mundo, construindo e atribuindo significados.

Desse modo, as novas formas de sociabilidade pressupõem a constituição de vínculos e relações possibilitadoras da circulação de bens simbólicos, dentre eles, a produção subjetiva relacionada ao cuidado em saúde mental para com a pessoa em adoecimento. Adoecimento considerado como dimensão existencial do sofrimento, o que implica não centralizar no transtorno ou na nosologia clássica, reconhecendo o contexto de pobreza e injustiças sociais. Logo, para subsidiar inovações em saúde mental, o que inclui práticas de cuidado e a construção de modelos voltados a processos avaliativos multidimensionais, dentre outros, precisamos transcender muitos limites que ainda marcam esse âmbito, expressos em nomenclaturas ainda presentes como louco ou loucura, que pouco ou nada nos dizem sobre o homem, sua existência e os condicionantes sócio-históricos de seu processo de adoecimento. Há, portanto, urgência por produção de novas respostas, de um novo ethos, uma nova atitude para com as pessoas em sofrimento existencial, o que exige, sobretudo, uma maior capacidade de pactuação, acolhimento e não anulação da diferença. É preciso produzir nos dispositivos de saúde mental novas formas de encontros, interessadas, sobretudo, na produção de vida.

Reconhecemos serem grandes os riscos de reprodução da prática asilar tradicional e excludente no cotidiano dos serviços desse campo. Não basta, 
portanto, garantir apenas no plano discursivo os novos projetos de produção de cuidado; há que inventar novos lugares sociais para a experiência de adoecimento.

Em uma perspectiva ético-politica, isso implica novas formas de ação social e política, bem como a abertura para novos paradigmas teóricos, epistemológicos, éticos e políticos. Tal posição abre a possibilidade de ampliação das estratégias de enfrentamento em prol da produção de uma nova cidadania (SANTOS, 2010), comprometida com a transformação da realidade vivida e potencializadora da indignação, do inconformismo e da ação qualitativamente emancipatória.

A transformação ou produção de novos cidadãos no campo da saúde mental é responsabilidade de todos os envolvidos, que se tornam hábeis em criar uma relação sustentada no compromisso, no diálogo, na autonomia e na afetação. Afetação originada na imersão da realidade, em que superamos os distanciamentos para com o outro, reconhecendo-nos como corresponsáveis pelos processos de exclusão e emancipação.

Desse modo, inovação aponta para a produção de um cuidado em saúde mental que vislumbra a potencialização da ação e o combate à banalização da exclusão e do preconceito, ainda muito presentes no contexto da saúde mental. Esses e vários outros elementos se diluem nas dimensōes epistêmica, ético-politica e ecológica que conformam o eixo da proposta aqui delineada voltada à inovação em saúde mental, possibilitando novas vias ou passagens mediante o cuidar de si sem deixar de cuidar do outro e do mundo, acolhendo diferenças e conflitos inerentes às relações sociais. Almejamos que os elementos discutidos ao longo deste texto possam subsidiar essa construção.

\section{Referências}

ALVERGA, A.R.; DIMENSTEIN, M. A loucura interrompida nas malhas da subjetividade. In: Amarante, P. (Org.). Archivos de Saúde Mental e Atenção Psicossocial 2. Rio de Janeiro: Nau, 2005, p. 45-66.

AMARANTE, P. A trajetória do Pensamento crítico em Saúde Mental no Brasil. In: Saúde Mental e Cidadania no contexto dos Sistemas Locais de Saúde. São Paulo: Hucitec, 1992. p. 103-119.

. (Org.) Psiquiatria Social e Reforma Psiquiátrica. Rio de Janeiro: Fiocruz, 1994. 202p. (Org.) O homem e a serpente: outras histórias para a loucura e a psiquiatria. Rio de Janeiro: Fiocruz, 1996. 
Loucos pela vida: a trajetória da reforma psiquiátrica no Brasil. Rio de Janeiro:

Fiocruz, 1998.

. A Clínica e a Reforma Psiquiátrica. In: . (Org.). Archivos de Saúde Mental e Atenção Psicossocial. Rio de Janeiro: Nau, 2003. p. 45-65.

ANDRADE, J.T; COSTA, L.F.A. Medicina complementar no SUS: práticas integrativas sob a luz da Antropologia médica. Saúde soc. [online], v. 19, n. 3, p. 497-508, 2010.

BARBIERI, J.C. et al. Inovação e sustentabilidade: novos modelos e proposições. RAE. São Paulo, v. 50, n. 2, abr./jun. p. 146-154, 2010.

BARROS, S.; OLIVEIRA, M.A.F.; SILVA, A.L.A. Práticas Inovadoras para o cuidado em saúde. Rev Esc Enferm USP. v. 41(Esp), p.815-9, 2007.

BEZERRA JR, B. Desafios da reforma psiquiátrica no Brasil. Physis: Revista de Saúde Coletiva, Rio de Janeiro, v. 17, n. 2, p.243-250, 2007.

BOFF, L. Espiritualidade: um caminho de transformação. São Paulo: Sextante, 2001.

BOHM, D. A Totalidade e a Ordem Implicada. São Paulo: Cultrix, 1998.

CAPRA, F. A teia da vida: uma nova compreensão dos sistemas vivos. São Paulo: Cutrix, 1996.

CARVALHO, L.B.; BOSI, M.L.M.; FREIRE, J.C. Dimensão ética do cuidado em saúde mental na rede pública de serviços. Rev Saúde Pública, v. 42, n. 4, p. 700-6, 2008.

CASTRO, D.E.; LIMA, E.M.F.A. Resistência, inovação e clínica no pensar e no agir de Nise da Silveira. Interface - Comunic, Saúde, Educ, v. 11, n. 22, p. 365-76, mai-ago 2007.

CAVALCANTE, R. et al., Educação Biocêntrica: um movimento de construção dialógica. Fortaleza: CDH, 2001.

CHAUI, M. O discurso competente. In: . (Org.). Cultura e democracia: o discurso competente e outras falas. São Paulo: Ed. Cortez, 2007.

CONDE, M.V.F.; ARAÚJO-JORGE, T.C. Modelos e concepções de inovação: a transição de paradigmas, a reforma da C\&T brasileira e as concepções de gestores de uma instituição pública de pesquisa em saúde. Ciência \& Saúde Coletiva, v. 8, n. 3, p. 727-741, 2003.

DIMENSTEIN , M. A reorientação da atenção em saúde mental: sobre a qualidade e humanização da assistência. Psicol. cienc. prof., v. 24, n. 4,Brasília, dez, 2004.

DELEUZE, G. Conversações. São Paulo: Editora 34, 1998.

FERREIRA, A.B.de H. Novo Aurélio século XXI: o dicionário da língua portuguesa. 3 ed. Rio de Janeiro: Nova Fronteira, 1999.

FRANCO, T.B. Produção do cuidado e produção pedagógica: integração de cenários do sistema de saúde no Brasil. Interface - Comunic., Saúde, Educ., v. 11, n. 23, p. 427-38, set-dez, 2007.

; MERHY, E.E. Atenção domiciliar na saúde suplementar: dispositivo da reestruturação produtiva. Ciência \& Saúde Coletiva, v. 13, n. 5, p. 1511-1520, 2008. 
FREIRE, P. Conscientização: teoria e prática da libertação: uma introdução ao pensamento de Paulo Freire. São Paulo: Cortez \& Moraes, 1979. . Pedagogia do Oprimido. Rio de Janeiro: Paz e Terra: 1983. 218p.

FUNG, M.; SIMPSON, S.; PACKER, C. Identification of innovation in public health. $J$ Public Health (Oxf), v. 33, n. 1, p. 123-130, June 2010.

GADAMER, H-G. O mistério da saúde: o cuidado da saúde e a arte da medicina. Lisboa: Ediçôes 70; 2002.

GODOY, M.G.C.; BOSI, M.L.M. A Alteridade no Discurso da Reforma Psiquiátrica Brasileira face à Ética Radical de Lévinas. Physis: Rev. Saúde Coletiva, v. 17, n. 2, p. 289-299, 2007.

GÓIS, C.W.L.G. Psicologia Comunitária: atividade e consciência. Fortaleza: Publicações Instituto Paulo Freire de Estudos Psicossociais, 2005.

INSTITUTO DE TECNOLOGIA SOCIAL. Reflexões sobre a construção do conceito de tecnologia social. In: Fundação Banco do Brasil. Tecnologia Social: uma estratégia para o desenvolvimento. Rio de Janeiro: EGB, 2004.

INOJOSA, R.M. O Acolhimento em rede. In: SECRETARIA MUNICIPAL DE SAÚDE, São Paulo. Acolhimento: o pensar, o fazer, o viver. São Paulo: Palas Athenas, 2002.

KIRMAYER, L.J. Asklepian dreams: the ethos of the wounded-healer in the clinical encounter. Transcult Psychiatry., v. 40, n. 2m p. 248-77, Jun 2003.

KOENIG, H.G. Religião, espiritualidade e psiquiatria: uma nova era na atenção à saúde mental. Rev. psiquiatr. clin. [online], v.34, suppl.1, p. 5-7, 2007.

LEVIN, R. Complexidade: a vida no limite do caos. Rio de Janeiro: Rocco, 1994.

LÉVINAS, E. Ética e infinito. Lisboa: Edições 70, 1982.

MAFFESOLI, M. A conquista do presente. Natal: Argos, 2001.

MARINOTTI, H. O Viver. In: SECRETARIA MUNICIPAL DE SAÚDE, São Paulo. Acolhimento: o pensar, o fazer, o viver. São Paulo: Palas Athenas, 2002.

MARTIN-BARÓ, I. Acción y Ideología: psicología social desde centroamérica. San Salvador: UCA Editores, 1985.

- Psicología de la liberación. Madrid: Editorial Trotta, 1998.

. Para uma Psicologia da Libertação. In: GUZZO, S.L.R.; LACERDA Jr., F.

(Orgs.). Psicologia Social para América Latina. São Paulo: Alínea, 2009.

MORIN, E; LE MOIGNE, G. A inteligência da complexidade. Petrópolis, Vozes, 2002.

NICÁCIO, F.; CAMPOS, G.W.S. A complexidade da atenção. Rev. Ter. Ocup. Univ. São Paulo, v. 15, n. 2, p. 71-81, maio-ago., 2004. 
PERES, J.F.P.; SIMAO, M.J.P.; NASELLO, A.G. Espiritualidade, religiosidade e psicoterapia. Rev. psiquiatr. clín. [online], v. 34, supl. 1, p. 136-145, 2007.

PINHEIRO, R.; GUIZARDI, F.L. Cuidado e integralidade: por uma genealogia de saberes e práticas no cotidiano. In: PINHEIRO, R.; MATTOS, R. A. (Org.). Cuidado: as fronteiras da integralidade. Rio de Janeiro: Cepesc, 2005. p. 21-36.

REEVES, H. A hora do deslumbramento. Lisboa: Gradativa, 1986.

ROSSI, R.R. El hombre como ser social y la conceptualización de la salud mental Positiva. Investigacion en Salud. Univ. de Guadalajara, v. VII, n. 2, p. 105-111, ago. 2005.

ROTELLI, F. A instituição inventada. In: ROTELLI, F.; LEONARDIS, O.; MAURI, D. (Org.). Desinstitucionalização. São Paulo: Hucitec, 2001. p. 89-100.

SANTOS, B. de S. Pela mão de Alice: o social e o político na pós-modernidade. São Paulo: Cortez, 2010.

SAWAIA, B.B. Comunidade: a apropriação científica de um conceito tão antigo quanto a Humanidade. In: SAWAIA, B.B. (Org.). Psicologia Social Comunitária: da solidariedade à autonomia. Petrópolis: Vozes, 1996. p. 35-55.

SCHUCH, E.M.M.; AXT, M.; TAROUCO, L.M.R. Linhas de fuga no processo artístico com a tecnologia digital. Novas Tecnologias na Educação, v. 1, n. 1, p. 1-12, 2003.

SERAPIONI, M. O papel da família e das redes primárias na reestruturação das políticas sociais. Ciência \& Saúde Coletiva, v. 10, sup, p. 243-253, 2005.

TORO, R. Teoria da Biodança: Coletânea de Textos. Fortaleza: ALAB, 2001.

VIEIRA, E.M. Atividade comunitária e conscientização: uma investigação a partir dos modos de participação social. 2008. 135p. Dissertação (Mestrado), Universidade Federal do Ceará, Curso de Psicologia, Fortaleza, 2008.

\section{Nota}

${ }^{1}$ Este texto integra os produtos de um dos projetos desenvolvidos pela equipe do LAPQS, com o apoio financeiro do CNPq (Edital MCT/CNPq/CT-Saúde/MS/SCTIE/DECIT 033/2008) e da FUNCAP - Fundação Cearense de Apoio ao Desenvolvimento Científico e Tecnológico ( Edital PPSUS-2009). 


\section{Innovation in mental health: subsidies for innovative practices and multidimensional evaluation models}

This study aims to discuss and to conceptualize the category innovation, in order to support the construction of innovative practices and multidimensional evaluation models in mental health. Innovation, a term very used in areas such as management, technology and in the hard sciences in general, is here reconfigured as process, pointing to movements of change, potentiating the emergence of new modes of interaction, news paradigms of knowledge and practices, whose character is to overcome previous logic, then considered traditional. Based on review and subsequent dialogue with the literature concerning mental health and the concept of innovation in this field, it is proposed to incorporate the epistemic dimensions, ethicalpolitical and ecological dimensions as essential elements to building practices and models of mental health care as well as proposals aimed to evaluate innovations. The epistemic dimension includes the necessary recognition of the disease in its existential dimension of suffering, overcoming the traditional taxonomy and nomenclature which tells us little or nothing about the man, his life and the socio-historical conditions of their suffering. The ethicalpolitical dimension understands the need to define mental health concepts covering transformative practices of social reality, incorporating a groupality, a category based on the circularity of care, creativity and social awareness. And finally, the ecological dimension means opening towards reconnecting with the cultural, cosmic and the transcendent, favoring processes that overcome the alienation and facilitate the development of personal and collective empowerment.

> Key words: innovation; mental health; health care; collective health; public health. 